Kidney

Blood Pressure Research

Achenbach, S. 280

Amann, K. 280

Augustin, W. 302

Besarab, A. 269, 363

Bocksch, W. 275, 290

Campean, V. 280

Carluccio, F. 295, 302

Dandel, M. 311

Dietz, R. 275

Fateh-Moghadam, S. 275, 290

Garlichs, C. 280

Gogoll, L. 353

Grune, T. 295, 302

Haller, C. 307

Hampl, H. 269, 295, 302, 353

Hennig, L. 353
Hetzer, R. 270, 311

Heusch, G. 349

Heyman, S.N. 325

Huehns, S. 275, 290

Kelm, M. 341

Kleinbongard, P. 341

Krabatsch, T. 270

Lehmkuhl, H.B. 311

Mueller, E. 275

Neureiter, D. 280

Nonnast-Daniel, B. 280

Peter, D. 302

Quast, S. 302

Radenkovic, S. 295

Rassaf, T. 341

Reiman, A. 280
Riedel, E. 353

Rosen, S. 325

Rosenberger, C. 325, 353

Runk, F. 280

Schartl, M. 290

Scherhag, A. 353

Schulz, R. 349

Sevanian, A. 302

Siems, W. 295, 302

Soman, S. 363

Varga, I. 280

Waigand, J. 275

Wiswedel, I. 302

Yeter, R. 270

\title{
Subject Index Vol. 28, No. 5-6, 2005
}

ACE inhibitor 349

Acute renal failure 325

Albumin 307

Anemia 295, 363

- management 353

Atherosclerosis 280, 302

AT1 receptor antagonist 349

Cardiac surgery 270

Chronic renal failure 280, 302

Coronary artery disease 270, 275, 290

- - sclerosis 280

Diabetes mellitus 353

Dialysis 270, 307

Endothelin 311

Endothelium 341

End-stage renal insufficiency 270

- _ disease 275, 302
Epoetins 363

Erythropoietin 295

Heart failure 349,363

- insufficiency therapy 353

Hemodialysis 295, 302, 353

Hydroxynonenal 295

Hypoxia-inducible factors 325

Inflammation 307

Intravascular ultrasound 290

Kidney disease 363

Left-ventricular hypertrophy 353

Lipid-lowering therapy 290

Lipid peroxidation 295, 302

Malnutrition 307

Malondialdehyde 295

Myocardial infarction 275

Nitric oxide 311,341
Oxidative stress 295, 302

Oxysterols 302

p53 325

Pathophysiology 363

Percutaneous coronary intervention 275

Phosphodiesterase inhibitors 311

Plaque calcification 280

- morphology 280

- regression 290

Prolyl-hydroxylase inhibition 325

Prostacyclin 311

Protein carbonyls 295

Pulmonary hypertension 311

Red blood cells 341

Renal interstitial fibrosis 325

Statins 290

Vascular calcification 280 